\title{
Changes in and predictors of pain and mortality in patients with chronic
}

\section{obstructive pulmonary disease}

\begin{abstract}
This longitudinal study of patients with chronic obstructive pulmonary disease (COPD) aimed to investigate changes in pain characteristics (i.e., occurrence, intensity, and interference) and covariates associated with pain from study enrollment to 12 months, and to investigate if the different pain characteristics were associated with 5-year mortality. In total, 267 patients with COPD completed questionnaires five times over 1 year. The mean age of the patients was 63 years (standard deviation: 9.0), 53\% were women, and 46\% had very severe COPD. Median number of comorbidities was 2.0 (range: $0-11$ ) and $47 \%$ of patients reported back/neck pain. Mixed models and Cox regression models were used for analyses. In total, $60 \%$ of the patients reported pain at baseline, and $61 \%$ at 12 months. The mixed model analyses revealed that those with better forced expiratory volume in 1 second (\% predicted), more comorbidities, only primary school education, and more respiratory symptoms reported significantly higher average pain intensity. Moreover, those with more comorbidities, more respiratory symptoms, and more depression reported higher pain interference with function. At the 5-year follow-up, 64 patients (24\%) were deceased, and the cumulative 5-year mortality rate was $22 \%$ (95\% confidence interval [19-25]). Older age, lower forced expiratory volume in 1 second (\% predicted), and higher pain interference at enrollment were all independently and significantly associated with higher 5-year mortality. Our findings show that many patients with COPD have persistent pain, and awareness regarding comorbidities and how pain interferes with their lives is needed.
\end{abstract}

Keywords: Chronic obstructive pulmonary disease, Longitudinal study, Mortality, Pain, Symptoms. 


\section{Introduction}

Dyspnea is the most common symptom in patients with chronic obstructive pulmonary disease (COPD) [1-4]. The severity of COPD is determined not only by pulmonary function, but also by risk of exacerbations, comorbidities, and certain symptoms (i.e., cough, phlegm, chest tightness, breathlessness, and sleep/energy) [5,6]. Pain is generally not among the listed symptoms, but occurs in 32-96\% of patients with COPD [7-9]. Severe/very severe pain intensity is reported in $18 \%$ of cases [7], while the reported mean level of pain interference with function is mild/moderate $[10,11]$.

Several explanations exist for pain in COPD. Systemic inflammation may induce neuropathic pain [12], thoracic pain may be caused by pleural elasticity loss [13], and pain can be related to comorbidities [14]. Many comorbidities, such as musculoskeletal disorders, heart diseases, and osteoporosis, may involve pain [7-9,15].

The relationship between demographic and clinical characteristics and pain in COPD is unclear and has been mainly investigated in cross-sectional studies. While no sex or age differences were found in two studies [11,16], others found a higher prevalence of pain in females $[17,18]$. Three studies found no relationship between pain and body mass index (BMI) $[11,16,18]$, while one study found significant relationships between BMI, pain intensity, and pain inference with function [19]. No significant relationship was found between pain and lung function [20]. A systematic review [9] showed a significant inverse correlation between lung function and pain prevalence. Patients with COPD with lower physical function reported higher pain severity [19].

Other symptoms are also common in patients with COPD, such as anxiety (30-90\%), depression $(13-70 \%)$ [ 1,4,21-25], fatigue $(55-77 \%)[1,26]$, and insomnia $(28-33 \%)[1,27]$. Some of these symptoms are negatively related to pain $[8,9]$, but only four cross-sectional 
studies have examined the relationships between these symptoms and pain; their findings are inconclusive $[1,18,20]$.

Few studies have examined pain changes in patients with COPD over time [25,28,29] and none of them examined broader spectrum changes or predictors of pain across the trajectory.

In the current sample of patients with COPD, $61 \%$ of patients reported pain at study enrollment [30] and 77\% reported pain over the following 12 months [31]. Higher depression was associated with higher average pain intensity and pain interference with function [30]. When examining profiles based on changes in pain occurrence and worst pain severity over 12 months, $48 \%$ of patients had a high probability of pain and $37 \%$ had moderate pain severity [31]. Additionally, females and those with higher BMI, more comorbidities, and less education were included in the pain groups [31].

Although mortality in patients with COPD is high [32], no studies have examined the association between pain and mortality. Determining pain characteristics that increase the mortality risk is necessary. Given the paucity and limitations of previous studies, this longitudinal study of patients with COPD aimed to investigate changes in pain characteristics (i.e., pain occurrence, average pain intensity, and pain interference with function) and covariates in the development of pain over 12 months and to examine predictors for 5 -year mortality.

\section{Methods}

\subsection{Patients and settings}

This longitudinal study is a part of a larger study of symptoms and immune markers in patients with COPD (ClinicalTrials.gov identification number: NCT01016587). The study procedures are described in detail elsewhere [30]. In brief, patients were recruited consecutively from three outpatient clinics and one referral hospital in the South-Eastern Norwegian Health Region 
between December 2009 and October 2012. Inclusion criteria were age > 18 years; diagnosed with moderate (grade II), severe (grade III), or very severe (grade IV) COPD according to the Global Initiative for Chronic Obstructive Lung Disease (GOLD) [5]; ability to read and understand Norwegian; and no cognitive impairments. Exclusion criteria were receiving ongoing treatment for pulmonary infection, COPD exacerbation, or cancer diagnosis at study enrollment. At enrollment (baseline) (T1), patients completed self-report questionnaires pertaining to information about demographic and clinical characteristics and multiple symptoms. The questionnaires were completed again 3 (T2), 6 (T3), 9 (T4), and 12 (T5) months after enrollment. In addition, clinical information was collected from the patients' medical journals.

The study was approved by the Regional Committees for Medical and Health Research Ethics (Reference number: S-09102a) and the privacy ombudsman at Oslo University Hospital. All patients provided written informed consent and they were guaranteed anonymity and confidentiality.

\subsection{Measurements}

\subsubsection{Demographic and clinical characteristics}

At enrollment, patients completed a demographic questionnaire pertaining to information such as age, sex, educational level, and cohabitation. Medical records were reviewed for information on patients' BMI, smoking history, number of years with COPD, emphysema, and chronic bronchitis. Chronic bronchitis was defined as daily productive cough lasting > 3 months for at least 2 consecutive years [5]. Diagnosis of emphysema was based on clinical assessment: chest configuration, chest radiography scans, diffusion capacity of carbon monoxide, and if available, chest computerized tomography scans. Pack-years of smoking were calculated as the average number of cigarettes smoked per day divided by 20 and multiplied by the total number of years of smoking [33]. 
Lung function was evaluated using spirometry. Forced expiratory volume in 1 second $\left(\mathrm{FEV}_{1}\right)$ and forced vital capacity $(\mathrm{FVC})$ were measured, and the predicted values were calculated according to the guidelines of the European Respiratory Society [34]. Disease severity was classified as mild ( $\mathrm{FEV}_{1} \geq 80 \%$ of predicted value), moderate ( $\mathrm{FEV}_{1}=50-79 \%$ of predicted value), severe $\left(\mathrm{FEV}_{1}=30-49 \%\right.$ of predicted value), and very severe (FEV $<30 \%$ of predicted value) according to the GOLD guidelines [5].

Exercise capacity was measured using the 6-minute walking test (6MWT) [35,36], which has satisfactory validity and reliability in patients with COPD [36,37]. Distance walked was measured to the closest meter.

\subsubsection{Comorbidities}

Comorbidities were assessed using the Self-Administered Comorbidity Questionnaire (SCQ19), which includes 16 common and three optional medical conditions [38]. In the present study, the frequencies of the different comorbidities as well as the total number of comorbidities were used.

\subsubsection{Pain and other symptoms}

Pain was evaluated using the Brief Pain Inventory (BPI) [39]. In the present study, pain occurrence, average pain intensity, and pain interference with function were evaluated. Patients who indicated that they were generally bothered by pain or who completed information on two of the four dimensions of the BPI (i.e., intensity, location, interference, and relief) were categorized into the pain group (i.e., pain occurrence: yes, no). Average pain intensity was examined using a numeric rating scale (NRS), with scores between 0 (no pain) and 10 (worst pain imaginable). Pain interference with function was examined for seven items (i.e., daily activity, mood, walking ability, normal work, sleep, enjoyment of life, and relations with others) using an 11-point NRS that ranged from 0 (does not interfere) to 10 (completely interferes). Total interference score was calculated as the mean of the seven items [39]. The BPI has been 
translated into Norwegian and has shown satisfactory reliability and validity [40,41] for patients with COPD [42]. The BPI has also shown to be sensitive to change in longitudinal studies $[43,44]$.

Breathlessness was assessed using the modified Medical Research Council (mMRC) dyspnea scale. The mMRC dyspnea scale is a 5-point rating scale that measures perceived respiratory disability based on the patients' own perception of functional limitation in daily activities. The scores can range from 0 (not troubled by breathlessness except during strenuous activities) to 4 (too breathless to leave house or breathless when dressing or undressing) $[5,45]$. The mMRC dyspnea scale has shown satisfactory reliability and validity [46,47], been translated into Norwegian, and been used in international and national guidelines for COPD $[5,48]$.

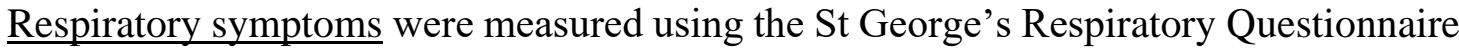
(SGRQ) [49], which is a disease-specific questionnaire used for evaluating the health status of patients with COPD. The questionnaire consists of 76 items divided into three components: symptoms, activity, and impact. A sum score is calculated for each component. Each component score can range from 0 to 100 , with a lower score indicating better health status. The symptom component consists of eight items, including frequency and distress from respiratory symptoms in terms of phlegm/sputum, shortness of breath, wheezing, and chest trouble $[49,50]$. The SGRQ has been translated into different languages and has satisfactory reliability and validity [49,51], including in Norwegian samples [52,53].

Anxiety was assessed using the state scale of the State-Trait Inventory (Form Y) (STAIS)[54]. STAI-S comprises 20 items evaluating the emotional responses of worry, nervousness, tension, and feelings of apprehension. Each item was rated on a Likert scale from 1 (not at all) to 4 (very much so). A total score ranging from 20 to 60 was calculated, with a higher score 
indicating more anxiety. A cutoff score $\geq 32.2$ indicates a high level of state anxiety [55]. The STAI-S is a reliable and valid instrument used to evaluate anxiety [54].

Depressive symptoms were assessed using the Center for Epidemiologic Studies Depression (CESD) scale [56]. The CESD scale consists of 20 items selected to represent clinical depression (i.e., depressed mood, feelings of guilt and worthlessness, feelings of helplessness and hopelessness, psychomotor retardation, loss of appetite, and sleep disturbance). Each item was rated on a 4-point Likert scale ranging from 0 (rarely or never) to 3 (most or all of the time). The total score was calculated by summing all items and ranges from 0 to 60 . A higher score indicates more depression. A score $\geq 16$ indicates clinically meaningful depressive symptoms. The CESD scale is a reliable and valid instrument used in research related to depression [56,57], and it has been used in a study of patients with cancer in Norway [58].

Sleep disturbance was assessed using the 21-item General Sleep Disturbance Scale (GSDS) [59]. The GSDS evaluates various aspects of sleep disturbance in the past week, and the frequency of each item is rated from 0 (never) to 7 (every day). The total score is a sum of the 21 items, ranging from 0 (no sleep disturbance) to 147 (extreme sleep disturbance). A score $\geq 43$ indicates high levels of sleep disturbance [59]. The instrument has established validity and reliability [59], and it has been used in a Norwegian study of patients with COPD [18].

Fatigue and energy were assessed using the 18-item Lee Fatigue Scale (LFS) that is used for evaluating how patients feel "right now" [60]. Each item was scored on a 0 to $10 \mathrm{NRS}$. The LFS comprises two subscales, i.e., fatigue and energy. The subscale scores were calculated as the mean of the items, ranging from 0 to 10 , with a higher score indicating higher levels of fatigue or energy. A score $\geq 4.4$ indicates high levels of fatigue, and a score $\leq 4.8$ indicates low levels of energy [60]. The LFS has established validity and reliability [61] and has been previously used in a Norwegian study of patients with COPD [18]. 


\subsection{Statistical analyses}

Demographic and clinical variables are described using mean, median, min/max, standard deviation (SD), and 95\% confidence interval (CI) for continuous data and using counts and percentages for categorical data. Crude associations between pairs of variables were assessed using $\chi^{2}$ test (categorical data) and independent $t$-test (continuous data).

To evaluate changes in pain characteristics (primary outcomes) (i.e., pain occurrence, average pain intensity, and pain interference with function) from the study enrollment to 12 months, and to assess the association of selected covariates (i.e., demographic, clinical, and other symptoms), generalized linear mixed models with logit link (for pain occurrence) and linear mixed models (for average pain intensity and pain interference with function) were used [62-64]. Based on the literature and clinical experience, the following variables were selected: demographic (covariates) (i.e., education and cohabitation) and clinical (covariates) (i.e., comorbidities, BMI, pack-years, number of years with COPD, emphysema, chronic bronchitis, and 6MWT) variables and symptoms (covariates) (i.e., respiratory symptoms, anxiety, depression, sleep disturbance, fatigue, and energy) variables. It is expected that these covariates are associated with different pain characteristics (i.e., pain occurrence, average pain intensity, and pain interference with function). In addition, all models were adjusted for age, sex and $\mathrm{FEV}_{1} \%$ predicted.

To determine which pain characteristics (i.e., pain occurrence, average pain intensity, and pain interference with function) are independently associated with 5-year mortality (secondary outcome), multivariate Cox regression models were fitted and adjusted for possible confounders (age, sex, and $\mathrm{FEV}_{1} \%$ predicted). The final model included only variables significantly associated with mortality. 
All tests were two-sided and a p-value $<0.05$ was considered statistically significant. Data were analyzed using IBM SPSS Statistics software (version 23; IBM SPSS, Armonk, NY, USA) and Stata version 14 software (StataCorp LP, College Station, TX, USA).

\section{Results}

Patient recruitment and compliance are outlined in Figure 1. A total of 363 patients were eligible for participation in the study, and 308 consented to participate. Of these, 267 (87\%) completed the questionnaire at enrollment and 194 also completed the questionnaire after 1 year (attrition rate, $27 \%)$. There were no statistically significant differences at enrollment in age $(p=0.637)$, sex $(p=0.096)$, or number of comorbidities $(p=0.512)$ between patients who did and those who did not complete the questionnaire during the 1-year follow-up. However, those who dropped out during the 1-year follow-up had lower lung function $(\mathrm{p}=0.008)$ at enrollment (baseline) than those who completed the study until the 1-year follow-up.

\subsection{Characteristics of the sample}

Demographic and clinical characteristics, comorbidities, and symptoms at enrollment and 1year follow-up are presented in Table 1. At enrollment, the mean age was 63.2 (SD: 9.0, $\min / \max : 36.8-83.7)$ years and $143(53 \%)$ were women. A total of $66 \%$ of the patients were married or lived with a partner, $89 \%$ had completed primary and secondary education, and $24 \%$ were current smokers. As many as 123 patients (46\%) had very severe COPD. The median number of comorbidities was 2.0 (min/max: $0-11)$ and $47 \%$ of the patients had back/neck pain, $24 \%$ headache, $19 \%$ osteoarthritis, and $19 \%$ heart disease. The mean score of respiratory symptoms (on SGRQ) was 61.5 (SD: 20.6, min/max: 0-100). The mean STAI-S score was 33.8 (SD: 8.6, min/max: 20.0-55.8) indicating a high level of anxiety, the mean sum GSDS score was 50.4 indicating a high level of sleep disturbance, and the mean LFS-energy score was 4.0 indicating a low level of energy. A more detailed overview of the demographic and clinical characteristics, and symptoms at enrollment and at 1-year follow-up are shown in Table 1. 


\subsection{Changes in pain occurrence over 1 year}

Occurrence of pain was stable over 1 year. At enrollment $(n=157)$ and 9-month $(n=120)$ follow-up, approximately $60 \%$ of patients reported pain; at 6-month $(n=129)$ follow-up, $58 \%$ reported pain; and at 3 - $(n=139)$ and 12 -month $(n=117)$ follow-up, $61 \%$ reported pain.

Table 2 shows associations between selected demographic, clinical, and symptom variables (T1) and pain occurrence during the 1-year follow-up (T1-T5). After adjustment for age, sex, and lung function $\left(\mathrm{FEV}_{1} \%\right.$ predicted), we found that female sex (odds ratio $(\mathrm{OR})=$ $0.60,95 \% \mathrm{CI}[0.45-0.80])$, better lung function $(\mathrm{OR}=0.98,95 \% \mathrm{CI}[0.97-0.99])$, only primary education $(\mathrm{OR}=1.94,95 \% \mathrm{CI}[1.19-3.17])$, higher number of comorbidities $(\mathrm{OR}=0.66,95 \%$ CI [0.59-0.73]), more respiratory symptoms (OR $=0.99,95 \%$ CI [0.98-0.99]), and depression $(\mathrm{OR}=0.97,95 \%$ CI $[0.96-0.99])$ were all independently and significantly associated with pain occurrence (Table 2).

\subsection{Changes in average pain intensity and pain interference with function over 1 year}

Both average pain intensity and pain interference with function remained almost unchanged during the 1-year follow-up period. At enrollment and 1-year follow-up, the mean average pain score was 3.14 (95\% CI [2.77-3.52]) and 3.19 (95\% CI [2.79-3.58]), respectively. The mean pain interference with function score was 2.55 at enrollment (95\% CI [2.18-2.92]) and 2.58 at 1-year follow-up (95\% CI [2.16-2.99]). A more detailed overview of the pain characteristics is presented in Figures 2 and 3 and Table 3.

Table 3 shows the contribution of demographic, clinical, and symptom variables (T1) toward average pain intensity and pain interference with function up to the 1-year follow-up (T1-T5). Multiple linear regression analysis revealed that patients with better lung function $(\mathrm{B}=0.01,95 \% \mathrm{CI}[0.00-0.02])$, higher number of comorbidities $(\mathrm{B}=0.53,95 \% \mathrm{CI}[0.44-$ $0.63])$, only primary school education $(\mathrm{B}=0.96,95 \% \mathrm{CI}[0.35-1.58])$, and more respiratory symptoms $(\mathrm{B}=0.02,95 \% \mathrm{CI}[0.01-0.03])$ reported significantly higher average pain 
intensity. Moreover, significantly higher pain interference with function was reported in patients with higher number of comorbidities $(\mathrm{B}=0.28,95 \% \mathrm{CI}[0.14-0.41])$, more respiratory symptoms $(\mathrm{B}=0.02,95 \% \mathrm{CI}[0.01-0.03])$, and more depression $(\mathrm{B}=0.11,95 \%$ CI $[0.09-0.14])$. In addition, those with emphysema $(\mathrm{B}=-0.56,95 \% \mathrm{CI}[-0.07-[-0.03]])$ reported significantly less pain interference with function. Gender was not associated with neither average pain intensity nor pain interference with function (Table 3).

\subsection{Five-year mortality and variables associated with mortality risk during 5-year follow-up}

After 5 years, 65 patients (24\%) were deceased and the cumulative 5-year mortality rate was $22 \%$ (95\% CI [19-25]). As outlined in Table 4, the multivariate Cox regression analysis revealed that older age (hazard ratio $(\mathrm{HR})=1.08,95 \%$ CI [1.05-1.12]), lower lung function $\left(\mathrm{FEV}_{1} \%\right.$ predicted $)(\mathrm{HR}=0.97,95 \% \mathrm{CI}[0.96-0.99])$, and higher levels of reported pain interference with function $(\mathrm{HR}=1.12,95 \% \mathrm{CI}[1.02-1.23])$ at enrollment were all independently associated with higher mortality risk at the 5-year follow-up. For each unit increase in the pain interference score, the mortality risk increased by approximately $12 \%$. Gender was not associated with mortality risk in these patients (Table 4).

\section{Discussion}

One of the main findings of the present study was that as many as $60 \%$ of patients with COPD experienced pain at enrollment into the study, and that the level of pain occurrence remained stable over 1 year. This rate of reported pain is similar to previous observations in terminally ill patients with COPD [29]. In addition, patients in the current study reported mild to moderate average pain intensity during the 1-year follow-up period. In summary, pain may be a persistent problem for patients with COPD over time. A stable prevalence of pain has also been observed among patients with COPD in primary care, where $46 \%$ of the patients had pain at enrollment into the study and $48 \%$ at 2-year follow-up [25]. 
When evaluating possible associations between selected covariates, low level of education was the only demographic variable that was significantly associated with both pain occurrence and average pain intensity over 1 year. The finding that patients with only primary school education had both a higher pain occurrence and a higher average pain intensity than those with university/college education is consistent with previous research findings [65].

Furthermore, patients with less severe COPD as measured by $\mathrm{FEV}_{1} \%$ predicted, those with more respiratory symptoms (i.e., chronic cough, sputum production, breathlessness, and wheezing), and those without emphysema more often reported pain during the 1-year followup period. The cause of the consistently high pain in patients with COPD is not clear. A simple, mechanical explanation may be that dyspnea and cough may induce pain for mechanical reasons, such as chronic strain on thoracic musculature and ligaments. In addition, structural changes caused by both chronic bronchitis and emphysema may by themselves induce pain [66,67]. Finally, hypoxemia may also be related to sensations of pain [68]. However, in our previous studies [30,31], we found that pain is actually more pronounced in patients with less severe COPD, suggesting that there may be other reasons for pain that are not directly related to the pulmonary disease. For instance, it is conceivable that comorbidities of the sort that frequently occur in patients with COPD may contribute to the sensation of pain. Supporting this notion, we found that the number of comorbidities in the present study was associated with pain occurrence and average pain intensity. Notably, patients in our study reported additional painful chronic conditions (e.g., back/neck pain, headache, heart disease, osteoarthritis, joint and connective tissue diseases, and rheumatoid arthritis) both at baseline and 1-year follow-up. This finding is consistent with previous research findings $[12,15,20]$ and may explain some of the pain in the patients with COPD in our study. Most of these conditions are also rather common in the general Norwegian population $[69,70]$. However, the high rates of back and neck pain (47\%) may be explained by the changes in respiratory function, remodeling of the thorax, and 
overuse of muscles in the back and neck [71-73]. Osteoporosis-related vertebral fractures are common in COPD [74], which often result in severe pain [75,76]. Moreover, headache is common in COPD and may result from chronic hypoxemia [68]. Furthermore, cardiovascular disease plays an important role in the clinical course of COPD [40]. Chest pain is frequent in COPD [70] and may be related to heart diseases, which are a common painful comorbidity in patients with COPD $[11,70,77]$. Our research group has revealed that as many as $85 \%$ of patients with heart failure reported pain and $43 \%$ stated that it was in the severe or very severe range [78]. In addition, there is evidence to suggest that the systemic inflammation associated with COPD may contribute to pain [12,28].

There may also be neurological or psychological causes for pain in COPD. The sensations of both pain and breathlessness are mediated within a larger brain network in the anterior insula [79]. In our study, depression was associated with both pain occurrence and pain interference with function during the 1-year follow-up period. While the causal association between depression and pain is not clear, the same neurological mechanisms are involved in the perception of both depression and pain [80]. The fact that patients with more depression reported a higher pain interference with function may reflect the "vicious COPD circle" [5]. Pain interference with function includes interference with daily functions such as general activity, mood, walking ability, normal work, relations with others, sleep, and enjoyment of life [39]. According to the "vicious COPD circle," patients with COPD experience shortness of breath that leads to decreased physical activity and physical function, which in turn might result in social isolation and depression [5]. Surprisingly, no significant relationship was found between anxiety, sleeplessness, fatigue, and pain in the present study, but the impact of other symptoms on pain in patients with COPD should be further investigated because it is known that symptoms might negatively affect each other and the patients' quality of life [81]. 
After 5 years, $24 \%$ of the included patients were deceased and the cumulative 5-year mortality rate was $22 \%$. This indicates that the mortality rate was stable over the 5 -year period. The mortality rate recorded in the present study is higher than that for patients with COPD admitted to hospital (7-19\%) [82,83] and intensive and critical care units (12\%) [82], and lower than that for patients with severe COPD receiving integrated care (39\%) [84]. One explanation for the high mortality rate may be the high prevalence rate of very severe COPD (GOLD IV) (46\%) [84]. Interestingly, older age, lower lung function, and higher pain interference with function at enrollment were associated with higher mortality rate. While the association between lower lung function and increased severity and mortality has been previously shown for COPD $[5,85,86]$, our finding of the effect of pain interference with function on mortality has not been previously reported. We found that for each unit increase in the pain interference score, the mortality risk increased by approximately $12 \%$. This finding emphasizes the importance of focusing on pain and how it impacts on the daily life of patients with COPD, and it suggests that it is not pain itself, but how it impacts on life that is important for the mortality in patients with COPD.

A lot of attention in the care of patients with COPD is focused on the respiratory function, our study shows that pain is a significant and long-lasting burden for these patients. We hope that our study may increase the awareness of pain in COPD patients, and that health care providers will pay attention to both comorbidities and pain interference regarding pain treatment in COPD patients. Further research warranted to increase the attention on how to best relieve pain in this vulnerable group of patients.

\subsection{Limitations}

Some limitations of the present study need to be acknowledged. The etiologies of pain and current treatments of pain and other symptoms were not evaluated in depth in the present study and should be examined in future research. Approximately $50 \%$ of the patients in the present 
study had very severe COPD and were recruited from a tertiary referral hospital. Therefore, results may not be generalizable to all patients with COPD. In addition, as we did not have a control group some of the findings might have been confounded [87]. Furthermore, those who dropped out during the 1-year follow-up period had a lower lung function ( $\mathrm{FEV}_{1} \%$ predicted) at enrollment than those who completed the study during the 1-year follow-up period. This may indicate that patients with the most severe disease dropped out of the study during the 1-year follow-up period, and we do not know how these patients would have affected our analyses. However, we found no significant differences at baseline in age, sex, or number of comorbidities between patients who did and did not drop out of the study during the 1-year follow-up period.

Finally, although the presented associations between lung function, respiratory symptoms, and pain are statistically significant, they are also limited in magnitude, which may indicate that their clinical relevance is uncertain.

\section{Conclusion}

Most of the patients with COPD included in the present study experienced pain continuously over 1 year and the pain intensity was mild to moderate. The pain was associated with COPDrelated comorbidities, respiratory symptoms, and depression, and pain interference with function was significantly associated with increased mortality within 5 years. The present study provides data to identify patients with COPD who are at risk of chronic pain and suggests that interventions to reduce pain over time are of vital importance.

\section{Conflict of interest statement}

The authors report no competing interests. We declare that the manuscript is original work and is not under consideration elsewhere. All authors have read and approved the paper.

\section{Acknowledgements}


We are grateful to all of the patients and clinicians who contributed to this study, especially the research nurses Gunilla Solbakk, Mari-Ann Øvreseth and Britt Drægni. 


\section{References}

[1] Bentsen, S.B., Gundersen D, Assmus J, Bringsvor H, Berland A. Multiple symptoms in patients with chronic obstructive pulmonary disease in Norway. Nurs Health Sci 2013;15:292-9. Doi: 1111/nhs.12031

[2] Blinderman, C.D. Homel, P. Billings, J.A. Tennstedt, S. Portenoy, R.K. Symptom distress and quality of life in patients with advanced chronic obstructive pulmonary disease. J Pain Symptom Manage 2009;38:115-23.

Doi:10.1016/j.jpainsymman.2008.07.006.

[3] Christensen, V.L. Rustoen ,T. Cooper, B. Miaskowski, C. Henriksen, A. Bentsen, S.B. Holm, A. Distinct symptom experiences in subgroups of patients with COPD. Int $\mathbf{J}$ Chron Obstruct Pulmon Dis 2016;11:1801-8. Doi.org/10.2147/COPD.S105299.

[4] Joshi, M. Joshi, A. Bartter, T. Symptom burden in chronic obstructive pulmonary disease and cancer. Curr Opin Pulm Med 2012;18:97-103.

Doi: 10.1097/MCP.0b013e32834fa84c.

[5] GOLD. Global initiative for chronic obstructive lung disease: Global strategy for the diagnosis, management, and prevention of chronic obstructive pulmonary disease. Global initiative for chronic obstructive lung disease, 2020. Available at: (https://goldcopd.org/wp-content/uploads/2019/12/GOLD-2020-FINAL-ver1.203Dec19_WMV.pdf). Accessed May 132020.

[6] Jones, P. Harding, G. Berry, P. Wiklund, I. Chen, H. Leidy, N. Development and first validation of the COPD assessment test. Eur Respir J 2009;34:648-54.

Doi: $\underline{10.1183 / 09031936.00102509}$

[7] Andenaes, R. Momyr, A. Brekke, I. Reporting of pain by people with chronic obstructive pulmonary disease (COPD): comparative results from the HUNT3 
population-based survey. BMC Public Health 2018;18:181. DOI: $\underline{10.1186 / \mathrm{s} 12889-}$ $\underline{018-5094-5}$

[8] Lee, A. Goldstein, R. Brooks, D. Pain and its clinical associations in individuals with chronic obstructive pulmonary disease (COPD): a systematic review. Chest 2015;147:1246-58. DOI: $\underline{10.1378 / \text { chest.14-2690 }}$

[9] van Dam van Isselt, EF. Groenewegen-Sipkema, K.H. Spruit-van Eijk, M. Chavannes, N.H. de Waal, M.W. Janssen, D.J. Achterberg, W.P. Pain in patients with COPD: a systematic review and meta-analysis. BMJ Open 2014;4:e005898.

DOI: $10.1136 /$ bmjopen-2014-005898.

[10] HajGhanbari, B. Holsti, L. Road, J.D. Ried, D.W. Pain in people with chronic obstructive pulmonary disease (COPD). Respir Med 2012;106:998-

1005. DOI: $\underline{10.1016 / \text { j.rmed.2012.03.004 }}$

[11] HajGhanbari, B. Yamabayashi, C. Garland, S. Road, J. Reid. W. The relationship between pain and comorbid health conditions in people with chronic obstructive pulmonary disease. Cardiopulm Phys Ther J 2014;25:25-35. DOI: 10.1097/01823246$\underline{201403000-00007}$

[12] Roberts, M. Mapel, D. Hartry, A. vonWorley, A. Thomson, H. Chronic pain and pain medication use in chronic obstructive pulmonary disease. A cross-sectional study. Ann Am Thorac Soc 2013;10: 290-8. Doi: 10.1513/AnnalsATS.201303-040OC.

[13] Bordoni, B. Marelli, F. Morabito, B. Castagna, R. Chest pain in patients with COPD: the fascia's subtle silence. Int J Chron Obstruct Pulmon Dis 2018; 13:1157-65. Doi: 10.2147/COPD.S156729. eCollection 2018.

[14] Putcha, N. Drummond, M.B. Wise, R.A. Hansel, N.N. Comorbidities and chronic obstructive pulmonary disease: Prevalence, influence on outcomes, and management. Semin Respir Crit Care Med 2015;36:575-91. DOI: 10.1055/s-0035-1556063 
[15] deMiguel, J. Lòpez-de-Andrès, A. Hernandez-Barrera, V. Jimenez-Trujillo, I. delBarrio, J. Puente-Maestu, L. Martinez-Huedo, M. Jimenez-Garacìa, R. Prevalence of pain in COPD patients and assocociated factors: Report from a population based study. Clin J Pain 2018;9:787-94. Doi: 10.1097/AJP.0000000000000598.

[16] Borge, C. Wahl, A. Moum, T. Pain and quality of life with chronic obstructive pulmonary disease. Heart Lung 2011;40:E90-101. DOI: 10.1016/j.hrtlng.2010.10.009.

[17] Janssen, D. Wouters, E. Parra, Y. Stakenborg, K. Franssen, F. Prevalence of thoracic pain in patients with chronic obstructive pulmonary disease and relationship with patient characteristics: a cross-sectional observational study. BMC Pulm Med 2016;16:47. DOI: $10.1186 / \mathrm{s} 12890-016-0210-8$.

[18] Borge, C.R. Wahl, A.K. Moum, T. Association of breathlessness with multiple symptoms in chronic obstructive pulmonary disease. J Adv Nurs 2010;66:2688-2700. DOI: $\underline{10.1111 / \mathrm{j} .1365-2648.2010 .05447 . x}$.

[19] HajGhanbari, B. Garland, S. Road, J. Reid, W. Pain and physical performance in people with COPD. Respir Med 2013;107:1692-9. DOI: 10.1016/j.rmed.2013.06.010.

[20] Bentsen, S.B. Rustøen, T. Miaskowski, C. Differences in subjective and objective respiratory parameters in patients with chronic obstructive pulmonary disease with and without pain. Int J Chron Obstruct Pulmon Dis 2012;7:137-43. Doi: 10.2147/COPD.S28994. Epub 2012 Feb 28.

[21] DiMarco, F. Verga, M. Reggente, M. Casanova, F. Santus, P. Blasi, F. Allegra, L. Centanni, S. Anxiety and depression in COPD patients: the roles of gender and disease severity. Respir Med 2006;100:1767-74. DOI: 10.1016/j.rmed.2006.01.026.

[22] Kunik, M. Roundy, K. Veazey, C. Souchek, J. Richardson, P. Wray, N. Stanley, M. Surprisingly high prevalence of anxiety and depression in chronic breathing disorders. Chest 2005;127:1205-11. DOI: $\underline{10.1378 / \text { chest.127.4.1205 }}$ 
[23] Panagioti, M. Scott, C. Blakemore, A, Coventry P. Overview of the prevalence, impact, and management of depression and anxiety in chronic obstructive pulmonary disease. Int J Chron Obstruct Pulmon Dis 2014;4:1289-1306. doi: 10.2147/COPD.S72073.

[24] vanMannen, J. Bindels, P. Dekker, F. Ijzermans, C. vanderZee, J. Schadè, E. Risk of depression in patients with chronic obstructive pulmonary disease and its determinants. Thorax 2002;57:412-6. doi: 10.1136/thorax.57.5.412.

[25] Walke, L. Byers, A. Tinetti, M. Dubin, J. McCorkle, R. Fried, T. Range and severity of symptoms over time among older adults with chronic obstructive pulmonary disease and heart failure. Arch Intern Med 2007;167:2503-8. doi: 10.1001/archinte.167.22.2503.

[26] Eckerblad, J. Todt, K. Jakobsson, P. Unosson, M. Skargren, E. Kentsson, M. Theander, K. Symptom burden in stable COPD patients with moderate or severe airflow limitation. Heart Lung 2014;43:351-57. doi: 10.1016/j.hrtlng.2014.04.004. Epub 2014 May 22.

[27] Budhiraja, R. Siddiqi, T.A. Quan, S.F. Sleep disorders in chronic obstructive pulmonary disease: etiology, impact, and management. J Clin Sleep Med 2015;11: 259-70. doi: $10.5664 / \mathrm{jcsm} .4540$.

[28] Pantilat, S. O'Riordan, D. Dibble, S. Langfeld, C. Longitudinal assessment of symptom severity among hospitalized elders diagnosed with cancer, heart failure, and chronic obstructive pulmonary disease. J Hosp Med 2012;7:567-72.

DOI: $\underline{10.1002 / \mathrm{jhm} .1925}$

[29] Romem, A. Tom, S. Beauchene, M. Babington, L. Scharf, S. Romem, A. Pain management at the end of life: a comparative study of cancer, dementia, and chronic obstructive pulmonary disease. Palliat Med 2015;15:464-9. 
[30] Christensen, V. Holm, A. Kongerud, J. Bentsen, S.B. Paul, S. Miaskowski, C.

Rustoen, T. Occurence, characteristics, and predictors of pain in patients with chronic obstructive pulmonary disease. Pain Manag Nurs 2016;17:107-18.

Doi.org/10.1016/j.pmn.2016.01.002

[31] Bentsen, S.B. Miaskowski, C. Cooper, B. Christensen, V. Henriksen, A. Holm, A. Rustoen, T. Distinct pain profiles in patients with chronic obstructive pulmonary disease. Int J Chron Obstruct Pulmon Dis 2018;13:801-11. doi: 10.2147/COPD.S150114.

[32] Mathers, C. Loncar, D. Projections of global mortality and burden of disease from 2002 to 2030. Plos Med 2006;3:2011-30. doi: 10.1371/journal.pmed.0030442.

[33] Larsson S. KOL. Kronisk Obstruktiv Lungsjukdom. [English: COPD. Chronic obstructive pulmonary disease]. Lund: Studentlitteratur, 2006 (Swedish).

[34] Quanjer, P.H. Tammeling, J.E. Cotes, J.E. Pedersen, O.F. Peslin, R. Yernault, J.C. Lung volumes and forced ventilatory flows. Report working party standardization of lung function tests European community for steel and coal. Official statment of the European respiratory society. Eur Respir J 1993;16:5-40.

[35] Butland, R. Pang, J. Gross, E. Woodcock, A. Geddes, D. Two-, six, and twelve-minute walking tests in respiratory disease. BMJ 1982;284:1607-8.

[36] Guyatt, G. Sullivan, M. Thompson, P. Fallen, E. Pugsley, S. Taylor, D. The 6-minute walk: a new measure of exercise capacity in patients with chronic heart failure. Can Med Assoc J 1985;132:919-23.

[37] Solway, S. Brooks, D. Lacasse, Y. Thomas, S. A qualitative systematic overview of the measurement properties of functional walk test used in cardiorespiratory domain. Chest 2001;119:256-70. doi: 10.1378/chest.119.1.256. 
[38] Sangha, O. Stucki, G. Liang, M. Fossel, A. Katz, J. The self administered comorbidity questionnaire: a new method to assess comorbidity for clinical and health services research. Arthritis Rheumatol 2003;49:156-63. doi: 10.1002/art.10993.

[39] Cleeland, C.S. Ryan, K.M. Pain assessment: global use of the Brief pain inventory. Ann Acad Med Singapore 1994;23:129-38.

[40] Klepstad, P. Loge, J. Borchgrevink, P. Mendoza, T. Cleeland, C. Kaasa, S. The Norwegian brief pain inventory questionnaire: translation and validation in cancer pain patients. J Pain Symptom Manage 2002;24:517-25. doi: 10.1016/s08853924(02)00526-2.

[41] Tan, G. Jensen, M. Thornby, J. Shanti, B. Validation of the brief pain inventory for chronic nonmalignant pain. J Pain 2004;5:133-7. doi: 10.1016/j.jpain.2003.12.005.

[42] Chen, Y. HajGhanbari, B. Road, J. Coxson, H. Camp, P. Reid, D. Reliabillity and validity of the Brief pain inventory in individuals with chronic obstructive pulmonary disease. Eur J Pain;2018:22;1718-26. doi: 10.1002/ejp.1258.

[43] Keller, S. Bann, C.M. Dodd, S.L. Schein, J. Mendoza, T.R. Cleland, C.S. Validity of the Brief Pain Inventory for use in documenting the outcomes of patients with non cancer pain. Clin J Pain 2004;20:309-17. doi: 10.1097/00002508-200409000-00005.

[44] Kroenke, K. Theobald, D. Wu, J. Tu, W. Krebs, E.E. Comparative responsiveness of pain measures in cancer patients. J Pain 2012,13:764-12. doi:

10.1016/j.jpain.2012.05.004.

[45] Fletcher, C. Standardised questionnaire on respiratory symptoms: a statement prepared and approved by the MRC Committee on the aetiology of chronic bronchitis (MRC breathlessness score). BMJ 1960;2:1665.

[46] Mahler, D. Wells, C. Evaluation of clinical methods for rating dyspnea. Chest 1988; 93:580-6. 
[47] Stenton, C. The MRC breathlessness scale. Occupational Med 2008;58:226-7. Doi: 10.1093/occmed/kqm162.

[48] Helsedirektoratet [English: Health Directorate]. Kols. Nasjonal faglig retningslinje og veileder for forebygging, diagnostisering og oppfølging. Norwegian. [English: COPD. National guidelines for prevention, diagnosis and follow up]. Oslo: Helsedirektoratet, 2012. Available at:

(https://www.helsedirektoratet.no/retningslinjer/kols/Kols\%20\%E2\%80\%93\%20Nasjo nal\%20faglig\%20retningslinje $\% 200 \mathrm{og} \% 20$ veileder\%20for $\% 20$ forebygging, $\% 20$ diagno stisering\%20og\%20oppf\%C3\%B8lging.pdf//attachment/inline/e974222b-9d84-4358$\underline{84 d 5-}$

9dd57b090786:ce015dd544648e3ae7bc4377269c52309a68aa77/Kols\%20\%E2\%80\%9 3\%20Nasjonal $\% 20$ faglig\%20retningslinje $\% 20 \mathrm{og} \% 20$ veileder $\% 20$ for $\% 20$ forebygging, \%20diagnostisering\%20og\%20oppf\%C3\%B8lging.pdf). Accessed May 122020.

[49] Jones, N.M. Quirk, F.H. Baveystock, C.M. The St George`s Respiratory Questionnaire. Respir Med 1991;85:25-35.

[50] Jones, P. St George's respiratory questionnaire Manual, version 2.3 2009. Available at: (http://www.healthstatus.sgul.ac.uk/SGRQ_download/SGRQ\%20Manual\%20June\%2 02009.pdf). Accessed May 132020.

[51] Bausewein, C. Farquhar, M. Booth, S. Gysels, M. Higginson, I.J. Measurement of breathlessness in advanced disease: A systematic review. Respir Med 2007;101:399410. doi: 10.1016/j.rmed.2006.07.003.

[52] Bentsen, S.B. Henriksen, A.H. Wentzel-Larsen, T. Hanestad, B.R. Wahl, A. What explain subjective health status in patients with chronic obstructive pulmonary disease: importance of symptoms in subjective health status of COPD patients. Health Qual Life Outcomes 2008; 6:8. doi: 10.1186/1477-7525-6-115. 
[53] Bringsvor, H.B. Langeland, E. Oftedal, B.F. Skaug, K, Assmus J, Bentsen, S.B. Selfmanagement and health related quality of life in persons with chronic obstructive pulmonary disease. Qual life res 2019;28:2889-99. https://doi.org/10.1007/s11136019-02231-8.

[54] Stanley, M. Beck, J. Zebb, B. Psychometric properties of four anxiety measures in older adults. Behav Res Ther 1996;34:827-38.

[55] Spielberger, C. State- Trait Anxiety Inventory: A comprehensive bibliography. Palo Alto, CA: Consultant Psycholopgists Press, 1984.

[56] Radloff, L. The CES-D scale: a self-report depression scale for research in general population. Center for epidemiologic studies national institute of mental health. Appl Psychol Meas 1997;1:385-401.

[57] Nishiyama, T. Ozaki, N. Iwata, N. Practice-baced depression screening for psychiatry outpatients: Feasibility comparison of two-types of center for epidemologic studies depression scales. J Adv Nurs 2009;63:632-8. doi: 10.1111/j.1440-1819.2009.02003.x.

[58] Astrup, G.L. Rustøen, T. Miaskowski, C. Paul, S. Bjordal, K. Changes in and predictors of pain characteristics in patients with head and neck cancer undergoing radiotherapy. Pain 2015;156:967-79. Dx.doi.org/10.1097/j.pain.0000000000142

[59] Lee, K. Self-reported sleep disturbances in employed women. Sleep 1992;15:493-8.

[60] Lee, K. Hicks, G. Nino-Murica, G. Validity and reliability of a scale to assess fatigue. Psychiatry Res 1991;36:291-98.

[61] Meek, P. Nail, L. Barsevick, A. Schwartz, A. Sharon, S. Whitmer, K. Beck, S. Jones, L. Walker, L. Psychometric testing of fatigue instruments for use with cancer patients. Nurs Res 2000;49:181-90. Doi: 10.1097/00006199-200007000-00001.

[62] Luke, D. Multilevel modeling. London: SAGE publications, 2004. 
[63] Twisk, J. Applied longitudinal data analysis for epidemiology. A practical guide. London: Chambridge University Press, 2013.

[64] Veierød, M. Lydersen, S. Laake, P. Medical statistics in clinical and epidemiological research. Oslo: Gyldendal Akademiske, 2012.

[65] Mundal, I. Bjorngaard, J. Nilsen, T. Nicoll, B. Grawe, R. Fors, E. Long-term changes in musculoskeletal pain sites in the general population: The HUNT study. J Pain 2016;16:30177-83. Doi.org/10.1016/j.jpain.2016.08.006

[66] Lohne, V. Heer, H.C.D. Andersen, M. Miaskowski, C. Kongerud, J. Rustøen, T. Qualitative study of pain of patients with chronic obstructive pulmonary disease. Heart Lung 2010;39:225-34. Doi.org/10.1016/j.hrtlng.2009.08.002

[67] O`Donell, D. Banzett, R. Carrieri-Kohlman, V. Casaburi, R. Davenport, P. Gandevia, S. Gelb, A. Mahler, D. Webb, K. Pathophysiology of dyspnea in chronic obstructive pulmonary disease. Am Thorac Soc 2007;4:145-68. Doi: 10.1513/pats.200611-159CC.

[68] Ozge, A. Ozge, C. Kalegasi, H. Yalin, O. Unal, O. Ozgur, E. Headache in patients with chronic obstructive pulmonary disease: effects of chronic hypoxaemia. $\mathbf{J}$ Headache Pain 2006;7:37-43. doi.org/10.1007/s10194-006-0264-8.

[69] Rustøen, T. Wahl, A. Hanestad, B.R. Lerdal, A. Paul, S. Miaskowski, C. Prevalence and characteristics of chronic pain in the general Norwegian population. Eur J Pain 2004;8:555-65. DOI: 10.1016/j.ejpain.2004.02.002.

[70] Bentsen, S.B. Rustøen, T. Miaskowski, C. Prevalence and characteristics of pain in patients with COPD compared to the Norwegian general population. J Pain 2011;12:539-45. DOI: 10.1016/j.jpain.2010.10.014.

[71] Kaperli, E. Vourazanis, E. Billis, E. Oldham, J. Strimpakos, N. Respiratory dysfunction in chronic neck pain patients. A pilot study. Cephalagia 2009;29:701-10. DOI: $\underline{10.1111 / \mathrm{j} .1468-2982.2008 .01787 . \mathrm{x}}$ 
[72] O'Sullivan, P. Beales, D. Changes in pelvic floor and diaphragm kinematics and respiratory patterns in subjects with sacroiliac joint pain following a motor learning intervention: a case serie. Man Ther 2007;12:209-18. doi:

10.1016/j.math.2006.06.006.

[73] Orozco-Levi, M. Structure and function of the respiratory muscles in patients with COPD: impairment or adaptation? Eur Respir J Suppl 2003;46:41-51s. doi:

10.1183/09031936.03.00004607.

[74] Biskobing, D.M. COPD and osteoporosis. Chest 2002; 121:609-20.

Doi: 10.1378/chest.121.2.609.

[75] Fahrleitner-Pammer, A. Langdahl, B. Martin, F.J. Karras, D. Barrett, A. Ljunggren, Ö. Walsh, J. Rajzbaum, G. Barker, C. Lems, W. Fracture rate and back pain during and after discontinuation of teriparatide: 36 month data from the European Forsteo Observational Study (EFOS). Osteoporos Int 2011; 22:2709-19.

DOI: $\underline{10.1007 / \mathrm{s} 00198-010-1498-5}$

[76] Lee, J. Song, J. Hootman, J. Semanic, P. Chang, R. Sharma, L. VanHorn, L. Bathon, J. Eaton, C. Hochberg, M. Jackson, R. Kwoh, C. Mysiw, W. Nevitt, M. Dunlop, D. Obesity and other modifiable factors for physical inactivity measured by accelerometer in adults with knee osteoarthritis. Arthritis Care Res 2013;65:53-61. Doi: 10.1002/acr.21754.

[77] Janssen, D. Spruit, M. Uszko-Lencer, N. Schols, J. Wouters, E. Symptoms, comorbidities, and health care in advanced chronic obstructive pulmonary disease or chronic heart failure. J Palliat Care Med 2011;14:735-43. Doi:

10.1089/jpm.2010.0479. 
[78] Rustøen, T. Stubbhaug, A. Eidsmo, I. Westheim, A. Paul, S. Miaskowski, C. Pain and quality of life in hospitalized patients with heart failure. J Pain and Symptom Manage 2008;36:497-504. doi: 10.1016/j.jpainsymman.2007.11.014.

[79] Lansing, R.W. Gracely, R.H. Banzet, R.B. The multiple dimensions of dyspnea: review and hypotheses. Respir Phys Neurobiol 2012; 167: 53-60.

DOI: $10.1016 /$ j.resp.2008.07.012

[80] Gatchel, R. Peng, Y. Fuchs, P. Peters, M. Turk, D. The biopsychosocial approach to chronic pain: scientific advances and future directions. Psychol Bull 2007;133:581624. Doi: 10.1037/0033-2909.133.4.581.

[81] Lim, K. Kim, S. Kim, H. Kim, S. Symptom Clusters and Quality of Life in Subjects with COPD. Respir Care 2017;62:1203-11. doi: 10.4187/respcare.05374.

[82] Brown, H. Dodic, S. Goh, S. Green, C. Wang, W. Kaul, S. Tiruvoipati, R. Factors associated with hospital mortality in critically patients with exacerbation of COPD. Int J Chron Obstruct Pulmon Dis 2018;13:2361-6. doi: 10.2147/COPD.S168983.

[83] Stenfors, N. Liaaen, D. Henriksen, A.H. No difference in long term survival in patients hospitalized for pneumonic versus non-pneumonic acute exacerbations of COPD. Clin Respir J 2018;12:1305-6. Doi: 10:1111/crj.12636

[84] Titova, E. Steinshamn, S. Indredavik, B. Henriksen, A.H. Long term effects of an integrated care intervention on hospital utilization in patients with severe COPD: a single centre controlled study. Respir res 2015;16:10.

Doi:10.1186/s12931-015-0170-1.

[85] Abukhalaf, J. Davidson, R. Villalobos, N. Meek, P. Petersen, H. Sood, A. Tesfaigzi, Y. Guillamet, R. Chronic obstructive pulmonary disease mortality, a competing risk analysis. Clin Respir J 2018;12:2598-2605. DOI: $\underline{10.1111 / \text { crj.12963 }}$ 
[86] Faner, R. Noell, G. Badia, J. Lòpez-Giraldo, A. Bakke, P. Silverman, E. Tal-Singer, R. Augusti, A. Distribution, temporal stability and association with all-cause mortality of the 2017 GOLD groups the ECLIPSE cohort. Respir Med 2018;141:14-9. Doi: 10.1016/j.rmed.2018.06.015.

[87] Shadis, W.R. Cook, T.D. Campbell, D.T. Experimental and quasi- experimental design for generalized causal inference. Boston: Houghton Miffilin Compamy, 2002. 


\section{Figure legends}

Figure 1. Flowchart of patient recruitment and compliance. Abbreviation: Lung Tx = lung transplantation.

Figure 2. Average pain intensity measured using a 10-point numeric rating scale (NRS) (mean, $95 \%$ confidence interval).

Figure 3. Pain interference with function measured using a 10-point numeric rating scale (NRS) (mean, 95\% confidence interval).

Eligible patients $(n=363)$

Declined to participate $(n=55)$

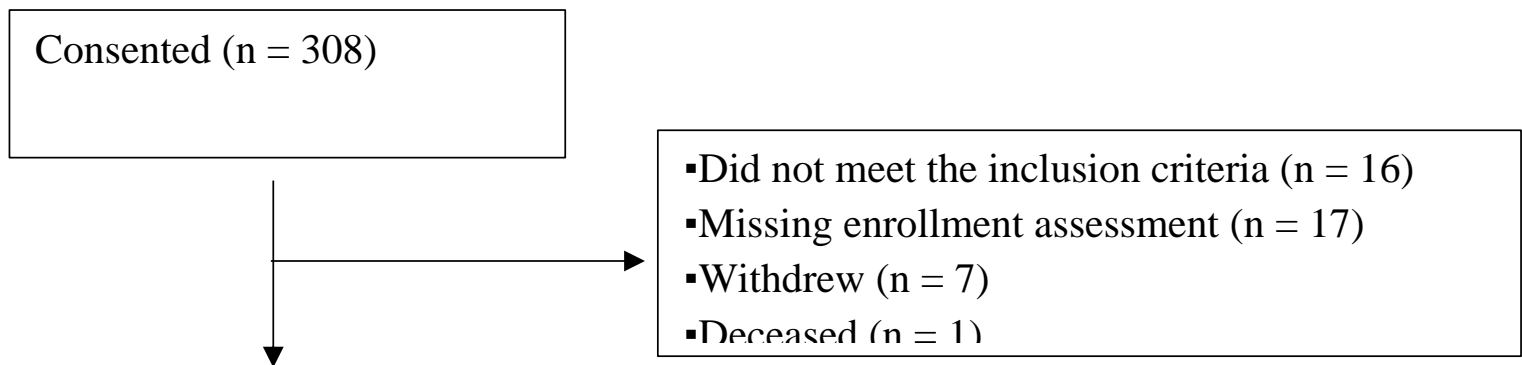

Enrollment $(\mathrm{n}=267)$

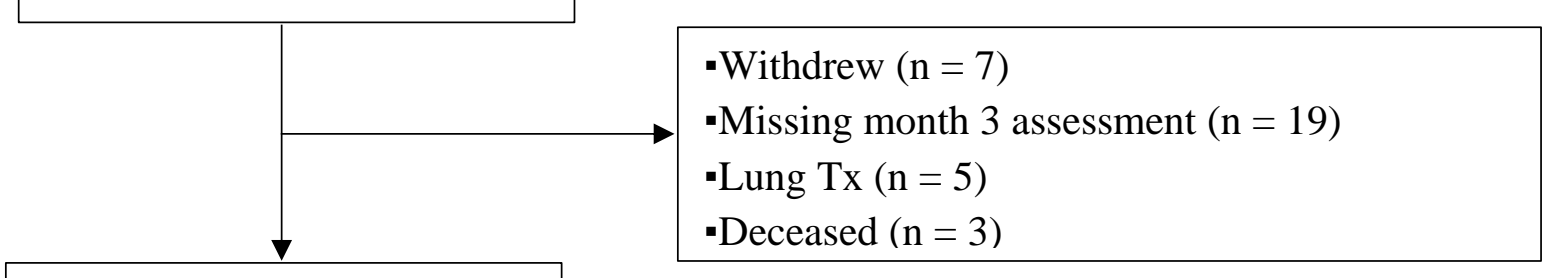

Month $3(\mathrm{n}=233)$

\begin{tabular}{|c|c|}
\hline & $\begin{array}{l}\text {-Withdrew }(\mathrm{n}=3) \\
\text {-Missing month } 6 \text { assessment }(\mathrm{n}=2) \\
\text {-Lung Tx }(\mathrm{n}=1) \\
\text {-Deceased }(\mathrm{n}=3)\end{array}$ \\
\hline \multicolumn{2}{|l|}{ Month $6(n=224)$} \\
\hline$\downarrow$ & $\begin{array}{l}\text {-Withdrew }(\mathrm{n}=4) \\
\text {-Missing month } 9 \text { assessment }(\mathrm{n}=11) \\
\text {-Lung Tx }(\mathrm{n}=8) \\
\text {-Deceased }(\mathrm{n}=1)\end{array}$ \\
\hline
\end{tabular}

Month $9(\mathrm{n}=200)$ 
-Lung Tx $(\mathrm{n}=4)$

-Deceased $(n=1)$

Month $12(\mathrm{n}=194)$

Figure 1. Flowchart of patient recruitment and compliance. Abbrevation: Lung Tx $=$ lung transplantation.

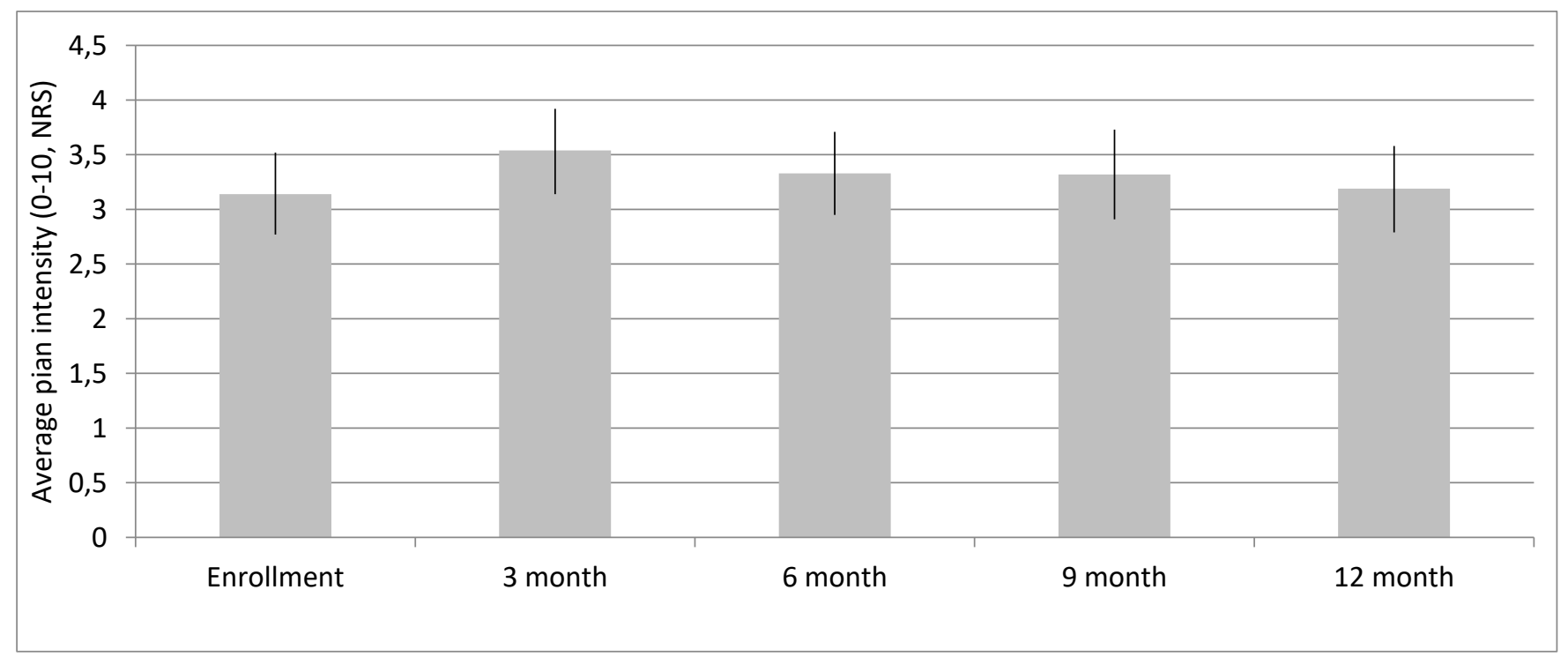

Figure 2. Average pain intensity measured using a 10-point numeric rating scale (NRS) (mean, 95\% confidence interval). 


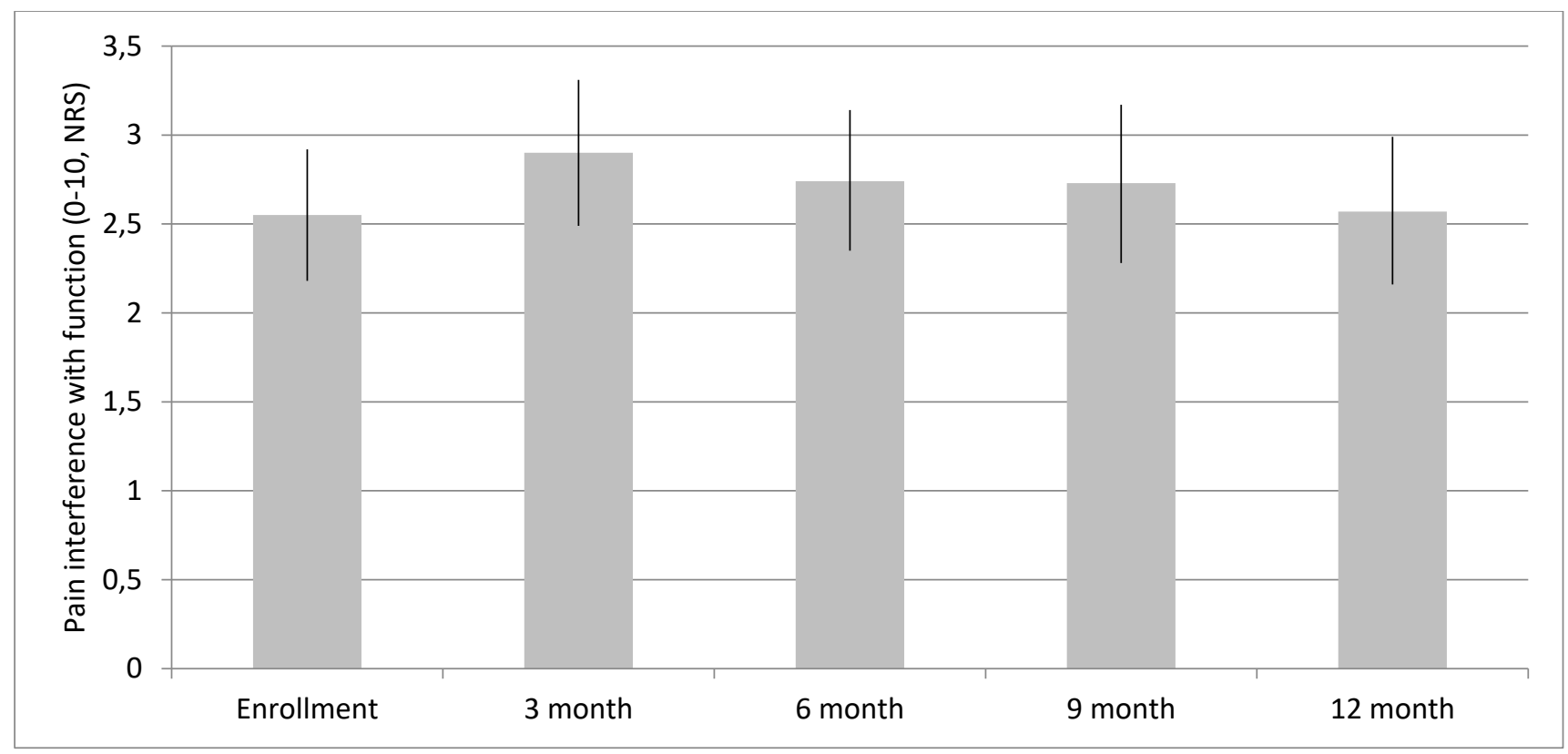

Figure 3. Pain interference with function measured using a 10-point numeric rating scale (NRS) (mean, 95\% confidence interval). 